MATEC Web of Conferences 13, 02010 (2014)

DOI: $10.1051 /$ matecconf/ 20141302010

(C) Owned by the authors, published by EDP Sciences, 2014

\title{
Effect of Low Pressure End Conditions on Steam Power Plant Performance
}

\author{
Syed Haider Ali , Aklilu Tesfamichael Baheta ${ }^{a}$ and Suhaimi Hassan \\ Department of Mechanical Engineering, Universiti Teknologi PETRONAS, Bandar Seri Iskandar, \\ Tronoh 31750, Perak, Malaysia
}

\begin{abstract}
Most of the electricity produced throughout the world today is from steam power plants and improving the performance of power plants is crucial to minimize the greenhouse gas emissions and fuel consumption. Energy efficiency of a thermal power plant strongly depends on its boiler-condenser operating conditions. The low pressure end conditions of a condenser have influence on the power output, steam consumption and efficiency of a plant. Hence, the objective this paper is to study the effect of the low pressure end conditions on a steam power plant performance. For the study each component was modelled thermodynamically. Simulation was done and the results showed that performance of the condenser is highly a function of its pressure which in turn depends on the flow rate and temperature of the cooling water. Furthermore, when the condenser pressure increases both net power output and plant efficiency decrease whereas the steam consumption increases. The results can be used to run a steam power cycle at optimum conditions.
\end{abstract}

\section{Introduction}

A steam power plant that operates on Rankine power cycle is one of the major power generation methods. The main components of this plant are the feed pump, the steam generator, turbine and condenser. Mountings and accessories are also part of the plant to control its operation and enhance the plant performance. The efficiency of the cycle depends on each component conditions. Condenser remains among one of the key components of a steam power plant that affect the plant performance. The main function of the condenser is to create vacuum pressure at the turbine exit so that the turbine specific power output increases. Consequently, low steam generation is required for a given power output and hence saves the cost of fuel. Secondly, to recover the condensate as a feedwater by rejecting its heat to circulating water which saves fresh water chemical treatment cost. Many efforts are going on to improve the performance of a condenser or heat exchangers from design point of view with different flow arrangements. Kim et al. [1] evaluated the flow distribution and thermal performance of a multi-pass, multi-channel heat exchanger as functions of the number of passes and inlet diameter. Chung et al. [2] examined the effect of flow distribution on the thermal performance of parallel flow heat exchanger by varying the design factors. Furthermore, operating the plant at optimum conditions is needed in order to get maximum power output to do this identifying the

${ }^{\mathrm{a} C}$ Corresponding author : aklilu.baheta@petronas.com.my

This is an Open Access article distributed under the terms of the Creative Commons Attribution License 2.0, which permits unrestricted use, distribution, and reproduction in any medium, provided the original work is properly cited. 
parameters and component/s that affect the performance significantly is important. In line with this, factors that reduce the efficiency of the condenser and power plant were studied by Haldkar et al. [3]. Dutta et al. [4] also studied the effect of cooling water temperature rise on Loss Factor and Efficiency of a condenser used in $210 \mathrm{MW}$ thermal power unit. From the review it is observed that if the condenser does not operate at proper conditions the desired output will not be achieved. Therefore, this study investigates in detail the low pressure end condenser conditions on a power plant performance.

\section{Modeling}

Steam surface condensers are the most commonly used condensers in modern power plants [5]. For the study the following are assumed, the heat exchanger is shell and tube type, there is no air leakage into the condenser and steady state conditions.

The mathematical model of the cycle is based on the mass conservation and the first law of thermodynamics. Designation of Figure 1 is used to analyse the cycle. The net power output and efficiency of the cycle are given by,

$$
\begin{gathered}
\dot{W}_{n e t}=\dot{W}_{t}-\dot{W}_{p}=\dot{m}_{s}\left[\left(h_{1}-h_{2}\right)-\int_{3}^{4} v d p\right] \\
\eta_{t}=\frac{\dot{W}_{n e t}}{\dot{Q}_{\text {in }}}
\end{gathered}
$$

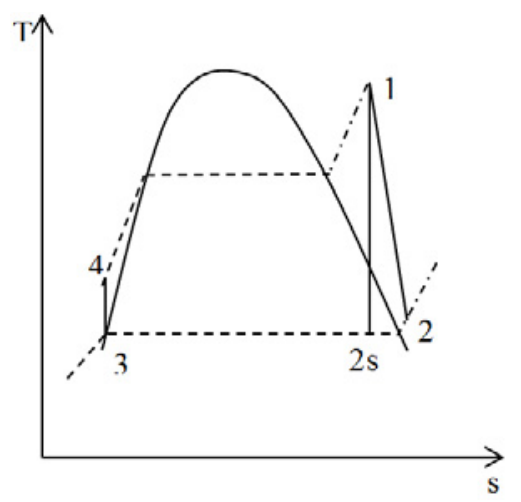

Figure 1. T-s diagram representation of a steam power plant cycle

The heat transfer in the condenser is given as [6]

$$
\begin{aligned}
\dot{Q}_{\text {cond }} & =\dot{m}_{s}\left(h_{2}-h_{3}\right) \\
& =\dot{m}_{c w} c_{p c w}\left(T_{c w, \text { out }}-T_{c w, \text { in }}\right) \\
& =A U \Delta T_{l m}
\end{aligned}
$$

where $\Delta T_{l m}=\frac{T_{c w, \text { in }}-T_{c w, \text { out }}}{\ln \left(\left(T_{s}-T_{c w, \text { out }}\right) /\left(T_{s}-T_{c w, \text { in }}\right)\right)}$

For the sake of investigation the heat transfer should be correlated to the cooling water inlet temperature, cooling water mass flow rate, the steam temperature and the overall heat transfer coefficient. This is eq. (6) which is obtained by equating eqs. (4) \& (5) and solving for the cooling water out let temperature and substituting this back into eq. (4). 


$$
\dot{Q}_{c o n d}=\dot{m}_{c w} c_{p c w}\left(1-e^{\left(\frac{-A U}{\dot{m}_{c w} c_{p c w}}\right)}\right)\left(T_{s}-T_{c w, i n}\right)
$$

Equating eqs. (3) \& (6) and solving for the steam flow rate gives

$$
\dot{m}_{s}=\dot{m}_{c w} c_{p c w}\left(1-e^{\left(\frac{-A U}{\dot{m}_{c w} c_{p w}}\right)}\right)\left(T_{s}-T_{c w, i n}\right) /\left(h_{2}-h_{3}\right)
$$

For the sake of simulation a one pass shell and tube heat exchanger was considered. The overall heat transfer coefficient was assumed to be $1500 \mathrm{~W} / \mathrm{m}^{2} . \mathrm{K}$ and using energy balance the area was estimated to be $205 \mathrm{~m}^{2}$. In addition, to simulate the cycle numerical values from available plant were used and tabulated in Table 1.

Table 1 Turbine operating data

\begin{tabular}{|l|c|}
\hline Steam inlet temperature $\left({ }^{\circ} \mathrm{C}\right)$ & 425 \\
\hline Steam inlet pressure $($ bar $)$ & 52 \\
\hline Steam flow rate $(\mathrm{kg} / \mathrm{s})$ & 3.5 \\
\hline Condenser pressure (bar) & 0.16 \\
\hline Shaft speed (rpm) & 12378 \\
\hline Nominal power $(\mathrm{kW})$ & 2970 \\
\hline
\end{tabular}

Equations 1 to 7 with Table 1 numerical values were used to simulate the low pressure end effect on the plant performance. For simulation purpose a simple subroutine developed in visual basic for excel application was used.

\section{Results and Discussion}

The performance of a steam power plant depends on the condenser pressure. Figures 2 (a) \& (b) show the effect of the condenser pressure on the plant efficiency and its net power output, respectively. As the condenser pressure increases both cycle thermal efficiency and the net power output decrease. The reason is the steam leaving the turbine has high enthalpy and this energy is rejected to the cooling medium in the form of waste. Furthermore, the main sources that affect the condenser pressure are air leakage, the cooling water mass flow rate and its temperature.

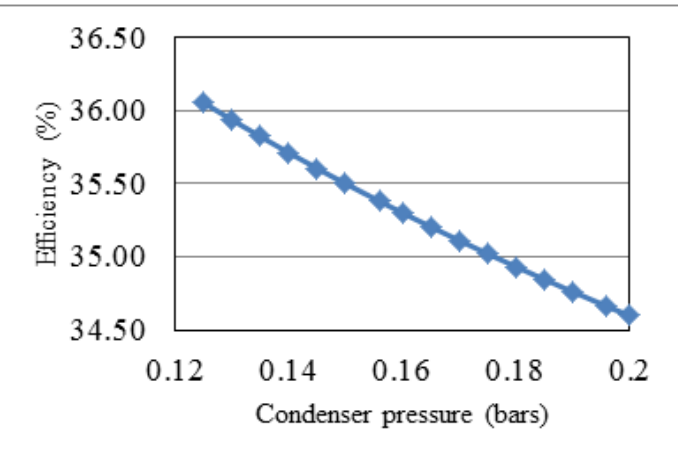

Figure 2 (a). Variation of thermal efficiency with respect to condenser pressure

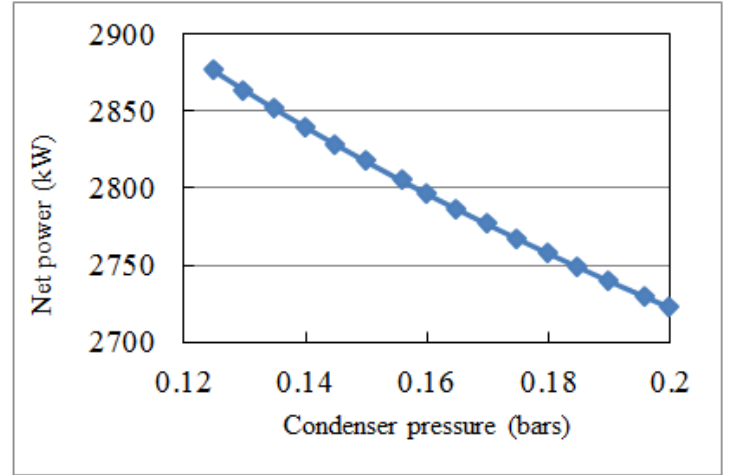

Figure 2 (b). Variation of net power with respect to condenser pressure 
Simulation was done to show the effect of cooling water temperature on the condenser pressure for $205 \mathrm{~kg} / \mathrm{s}$ cooling water flow rate and $6800 \mathrm{~kW}$ condenser heat transfer load. As indicated in Figure 3 when the cooling water temperature increases the condensing pressure increases. Naturally the cooling water temperature changes with the seasonal change. Because either it comes from the natural water sources for one through cooling system or in closed system after it was cooled down in a cooling tower. Furthermore, the cooling tower effectiveness and the water source temperature depend on the weather data. Therefore, when the cooling water temperature increases to maintain the condenser pressure its mass flow rate should be increased.

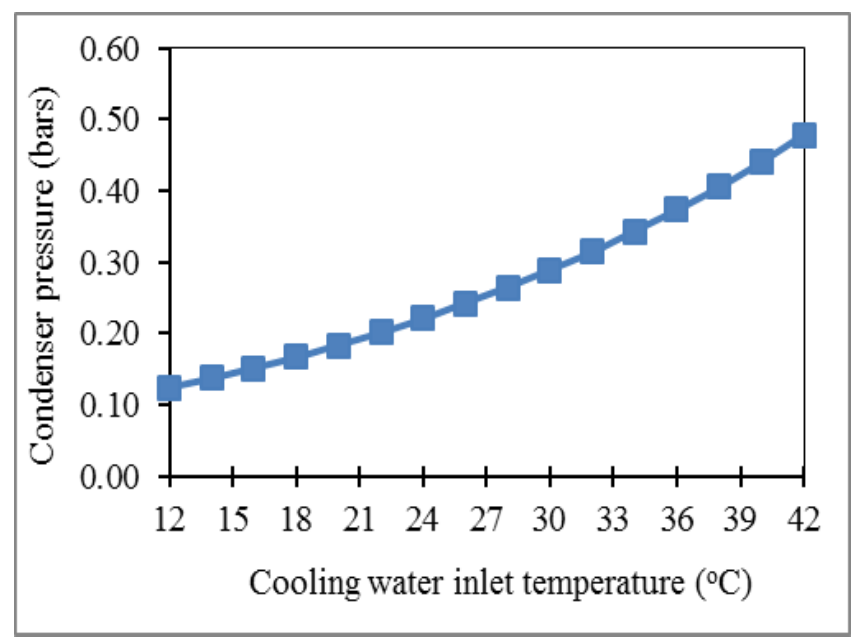

Figure 3. Condenser pressure variations with respect to cooling water temperature for $205 \mathrm{~kg} / \mathrm{s}$ cooling water flow rate and $6800 \mathrm{~kW}$

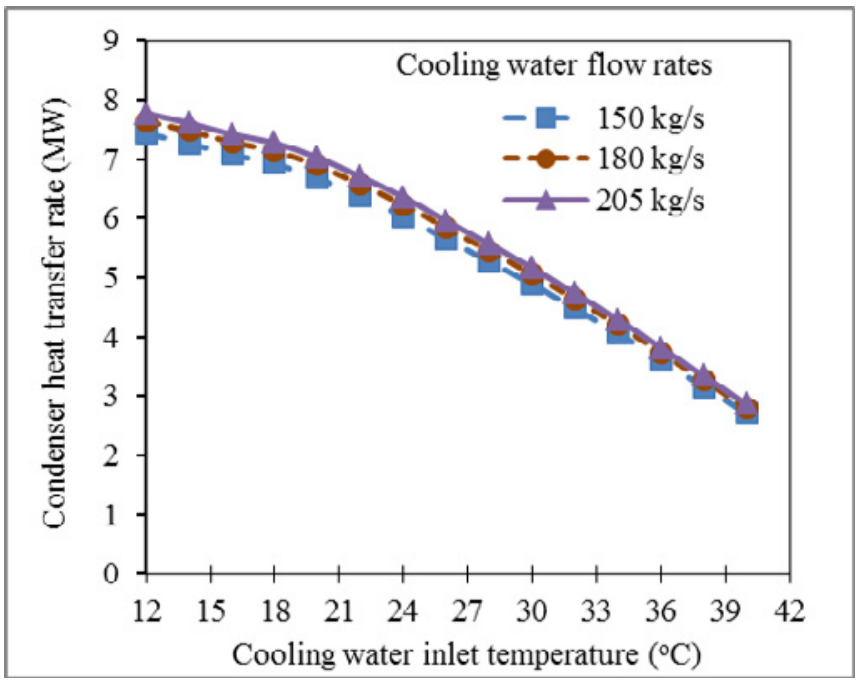

Figure 4. Variation of condenser heat transfer rate with respect to cooling water temperature at a given condenser pressure condenser heat transfer load.

Variation of the condenser heat transfer rate with respect to cooling water inlet temperature for different cooling water flow rates is shown in Figure 4. The heat transfer rate decreases as the inlet cooling water temperature increases because for a given condenser steam temperature when the cooling water inlet temperature increases the temperature gradient between the two streams decreases 
which results less heat transfer. Furthermore, at a given cooling water temperature the higher the flow, the higher is the heat transfer as mass flow rate is directly proportional to heat transfer.

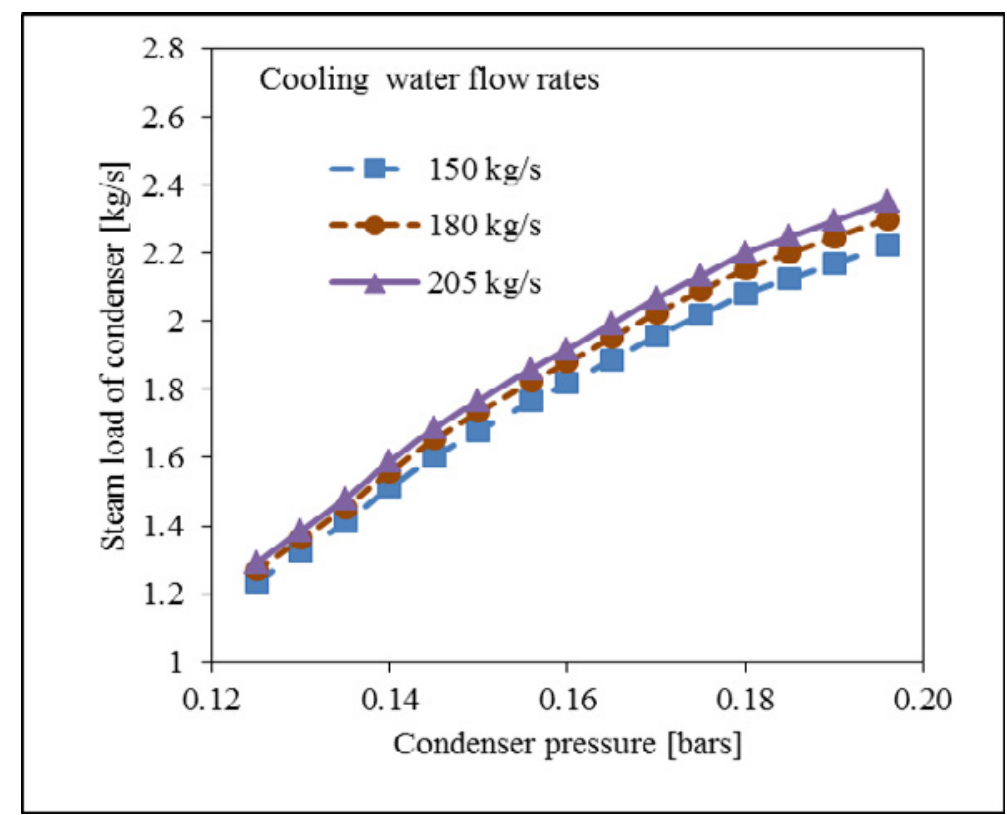

Figure 5. Condenser steam load versus condenser pressure for different cooling water mass flow rates at constant cooling water inlet temperature

The steam load on the condenser depends on its pressure for a given cooling water inlet temperature. As indicated in Figure 5 as the condenser pressure increases the steam entering to the condenser increases. The main reason is when the condenser pressure is high, the turbine is exit enthalpy is high and the specific turbine power output is low. Therefore, to achieve the required turbine power output it uses higher steam flow rate and hence the condenser steam load increases. Moreover, for a given condenser pressure the less the cooling water mass flow rate, the higher is the steam load on the condenser. All in all, continuous condenser operating parameters should be monitored and necessary adjustment has to be made to achieve the optimum cycle efficiency and specific power output.

\section{Conclusions}

A Rankin power cycle was modeled thermodynamically. The model was used to simulate the condenser operating parameters effect on the cycle thermal efficiency and its specific power output assuming no air leakage into the condenser. The steam power plant strongly depends on its low pressure end operating conditions, where the condenser is the key for the heat exchange. Generally as the condenser pressure increases both thermal efficiency and net power output decrease whereas the steam consumption increases. Condenser pressure is affected by the cooling water temperature and mass flow rate. The smaller the cooling water flow rate for a given cooling water inlet temperature, the higher will be the condenser pressure. Cooling water temperature may vary as the season change in a year and hence its mass flow rate should be varied to maintain the condenser set pressure in order to get the optimum cycle efficiency and power output. 


\section{Acknowledgments}

The authors wish to thank Universiti Teknologi PETRONAS for providing financial support and the required support to do the study.

\section{Nomenclature}

$\dot{W}=$ power

$\dot{Q}=$ heat transfer rate

$\dot{m}=$ mass flow rate

$h=$ enthalpy

$v=$ specfic volume

$p=$ pressure

$T=$ temperature

$c_{p}=$ specfic heat

$A=$ surface area

$U=$ overall heat transfer coefficien $\mathrm{t}$

\section{Subscripts}

$t=$ turbine

$p=$ pump

$s=$ steam

$c w=$ cooling water

cond $=$ condenser

\section{References}

1. M.S. Kim, K.S. Lee, S. Song, Effects of pass arrangement and optimization of design parameters on the thermal performance of a multi pass heat exchanger, International Journal of Heat and Fluid Flow, 29: 352-363 (2008)

2. K. Chung, K.S. Lee, W.S. Kim, Optimization of the design factors for thermal performance of a parallel-flow heat exchanger, International Journal of Heat and Mass Transfer, 45 (24): $4773-$ 4780 (2002)

3. Vikram Haldkar, Abhay Kumar Sharma, R.K. Ranjan, V.K. Bajpai, Parametric Analysis of Surface Condenser for Thermal Power Plant, International Journal of Thermal Technologies ISSN 2277 - 4114 ( 2013)

4. A. Dutta, A.K. Das, S. Chakrabarti, Study on the effect of cooling water temperature rise on loss factor and efficiency of a condenser for a $210 \mathrm{MW}$ thermal power unit, International Journal of Emerging Technology and Advanced Engineering, 3, special issue 3: pages 485-489 (ICERTSD 2013)

5. R.K. Kapooria, S. Kumar, K.S. Kasana, An analysis of a thermal power plant working on a Rankine cycle: A theoretical investigation, Journal of Energy in Southern Africa, 19 ( 2008)

6. F.P. Incropera, D.P. Dewitt, Fundamentals of Heat and Mass Transfer (John Wiley \& Sons, Inc., New York, 2007) 